\title{
Oviposition Preference of Bactrocera zonata (Saunders) on Different Fruits under Laboratory Conditions
}

\author{
Ghulam Murtaza $^{1 *}$, Muhammad Ramzan ${ }^{2}$, Assad Ullah ${ }^{3}$, Abid Ali ${ }^{5}$, Ayesha Zafar ${ }^{3}$, Rukhsar Beanish ${ }^{3}$, \\ Ahmad Ali ${ }^{4}$, Ghulam Mustafa ${ }^{4}$ and Mudassar Aslam ${ }^{4}$
}

${ }^{1}$ Department of Entomology, College of Plant Protection, China Agricultural University, Beijing, China; ${ }^{2}$ State Key Laboratory for Biology of Plant Disease and Insect Pests, Institute of Plant Protection, Chinese Academy of Agricultural Sciences, Beijing 100193, China; ${ }^{3}$ Department of Zoology Wildlife and Fisheries, University of Agriculture, Faisalabad, Pakistan; ${ }^{4}$ Department of Entomology, University of Agriculture, Faisalabad, Pakistan; ${ }^{5}$ Department of Biology, Govt. Degree College, Akbarpura, Nowshera, Pakistan.

\begin{abstract}
Fruit fly, Bactrocera zonata (Saunders) is the most important pest in different regions of the world. Due to cosmopolitan in nature, it causes huge losses in various fruits and vegetables production throughout the globe. The current experiment was designed at Insect Rearing Laboratory, MNS. University of Agriculture, Multan to evaluate host and oviposition preference of Bactrocera zonata on different fruits under laboratory conditions. Infested fruits were collected from local fruits and vegetables market and brought to laboratory. Collected fruits and vegetables were placed in cages having sand in bottom for pupation. After the adult emergence fruit fly species were identified based on diagnostic morphological features and placed in separate cages. Different fruits such as guava, apple, fig, banana and citrus were exposed to Bactrocera zonata for oviposition. Fruits were placed in cage to assess the host preference for oviposition fruits having equal weight $(500 \mathrm{~g})$. Fifty pairs of $11-12$ days old adult of B. zonata were released in cage for $24 \mathrm{~h}$ to determine their oviposition. The study resulted that maximum number of pupae (125.34) were formed in guava fruit exposed to B. zonata followed by banana (104.12), citrus (98.65), fig (84.34) and apple fruit (34.27). The adult emergence percentage was maximum in guava (79.26\%) and banana (70.56\%) host followed by citrus (65.44\%), fig (57.61\%) and apple fruit (53.51\%) respectively. The study concluded that guava was the most preferred and suitable host for oviposition. Furthermore, the oviposition preference shifted towards the suitable host if a suitable host choice was available at breading site.

Received | November 27, 2020; Accepted | July 01, 2021; Published | August 15, 2021

*Correspondence | Ghulam Murtaza, Department of Entomology, College of Plant Protection, China Agricultural University, Beijing, China; Email: murtazabwn54@gmail.com

Citation | Murtaza, G., M. Ramzan, A. Ullah, A. Ali, A. Zafar, R. Beanish, A. Ali, G. Mustafa and M. Aslam. 2021. Oviposition preference of Bactrocera zonata (Saunders) on different fruits under laboratory conditions. Pakistan Journal of Agricultural Research, 34(4): 689-692.

DOI | https://dx.doi.org/10.17582/journal.pjar/2021/34.4.689.692

Keywords | Bactrocera zonata, Emergence, Host preference, Oviposition, Multan
\end{abstract}

\section{Introduction}

$\mathrm{F}$ ruit fly belongs to order Diptera and family Tephritidae is most important pest in different regions (tropical, sub-tropical and temperate) of the world (De Meyer et al., 2010; Vargas et al., 2015) and attain international attention due to cosmopolitan in nature (Rasool et al., 2017). Most species are polyphagous in nature and damage a wide range of fruits and vegetables (Joomaye et al., 2000; Rauf et al., 2013). There are 5,000 documented species in Tephritidae family under 6 subfamilies and 500 
genera throughout the world (Uchoo and Nicacio, 2010). About 70 species of fruit flies are considered important pest of different agricultural and horticultural crops in tropical and subtropical areas of the globe (Ni et al., 2012).

Genus Bactrocera is a major threat to horticultural crops due to invasive potential and wide range of hosts (Clarke et al., 2005). Bactrocera species are causing huge losses at national and international level. Approximately 11 species have reported from Punjab Pakistan and directly and indirectly cause severe losses (Zubair et al., 2019). Among reported species, two polyphagous fruit flies such as Bactrocera zonata and Bactrocera cucurbitae are more threating and prevalent in all districts of Punjab especially south Punjab (Sarwar et al., 2013).

$B$. zonata feed on more than 50 fruits and vegetables like guava, mango, peach, citrus, pumpkin, bitter gourd and apricot (El-Akhdar and Afia, 2009; Sarwar et al., 2013).The female fruit fly lays eggs in the soft and tender tissues by piercing them with the ovipositor; resulting a watery fluid oozing from the puncture and maggots developing inside the fruits (Jackson et al., 2003). Female adult fruit fly visits the fruit and make decision to oviposit in host fruit after determination that host is suitable for their progeny (Joachim-Bravo et al., 2001; Fontellas-Brandalha and Zucoloto, 2004). The female fruit fly determines host/food distance using sensory organ with the help of sensory receptors. Female uses odor receptors to locate food source from a long distance. After the selection of host on morphological basis fruit fly land and take a taste bite that food is suitable or not for their progeny survival based on food nutrition and host defense toxicity (Wisotsky et al., 2011). Host appearance such as color, size, shape and fragrance of host fruit these factor influence females to host rejection or acceptance (Mahfuza et al., 2011).

Knowledge about its host preference will be helpful to manage this pest by using this host as a trap crop. Therefore, the present study was intended to evaluate host preferences for oviposition under laboratory conditions. This study will also be helpful for host preference surveillance sampling of fruit fly if they are not attracted to different male lure.

\section{Materials and Methods}

Collection of culture

Different infested fruits like guava, citrus and banana etc. were collected from local fruit and vegetable market in Multan.

\section{Rearing and identification of fruit fly}

Collected infested fruits having maggots were brought to the Insect rearing laboratory, MNS. University of Agriculture, Multan during 2020. Infested fruit were placed in mosquito net cage for pupation and adult emergence. When adult emerged, they identify based on diagnostic morphological features and placed in separate cages. Identified B. zonata adults were reared on banana fruit. The culture was maintained at $26 \pm 2$ ${ }^{\circ} \mathrm{C}$ temperature and $65 \% \pm 5 \%$ relative humidity.

\section{Host preference and female oviposition}

Different fruits like as guava, citrus, banana, fig and apple were used in the experiment for host preference test. All fruits were placed in mosquito net cage with $500 \mathrm{~g}$ each fruit and 50 pair of 11-12 days old adults of $B$. zonata were released to observe oviposition for $24 \mathrm{~h}$. After 24 hours of post treatments, female oviposited fruits were placed in separate plastic cages having sand for pupation. After pupation, sand was sieved and fresh pupa was collected. Counted number of pupae form each host were placed in separate small plastic cages for adult emergence. Host preference were evaluated based on total number of pupae, number of adult emergence and adult emergence percentage. Adult emergence percentage was determined from the total number of pupae formed divided by number of adults emerged multiply with hundred in all commodities.

\section{Statistical analysis}

The collected data of fruit infesting and adult emergence were arranged in excel sheet and determine the analysis of variance (ANOVA) by using statistical software, Statistix 8.1 The mean value of treatments was evaluated using least significant difference (LSD) test at $\mathrm{P}=0.05$ probability level.

The adult emergence (\%) was calculated by following formula:

Adult Emergenmce $(\%)=\frac{\text { Number of adults emerged }}{\text { Total number of pupae }} \times 100$

\section{Results and Discussion}

The preference of host suitability for fruit fly oviposition was tested on five fruits under laboratory conditions. 
Host suitability is the most important for the survival of their progeny. The female fruit fly visits the hosts and selection was done based on host color, size, shape and smell which influence the female fruit fly's response (Mahfuza et al., 2011). In the present study guava was most preferred host for oviposition. The number of pupae and adult's emergence from guava fruit was recorded maximum (125.34 pupae and 98.35 adult emerged). The minimum number of pupae formation and adult's emergence was recoded from apple fruit used as host. The percentage of adult emergence was recorded maximum in guava (79.26\%) and banana (70.56\%) followed by citrus (65.44\%), fig (57.61\%) and apple fruit (53.51\%), respectively (Table 1 ).

Table 1: Host preference of Bactrocera zonata for oviposition on different fruits.

$\begin{array}{lllll}\text { No. } & \text { Host } & \begin{array}{l}\text { No. of } \\ \text { pupae }\end{array} & \begin{array}{l}\text { Adult } \\ \text { emerged }\end{array} & \begin{array}{l}\text { Emergence } \\ \text { percentage }\end{array} \\ 1 & \text { Guava } & 125.34 \mathrm{a} & 98.35 \mathrm{a} & 79.26 \mathrm{a} \\ 2 & \text { Citrus } & 98.65 \mathrm{c} & 64.56 \mathrm{c} & 65.44 \mathrm{~b} \\ 3 & \text { Banana } & 104.12 \mathrm{~b} & 73.47 \mathrm{~b} & 70.56 \mathrm{~b} \\ 4 & \text { Apple } & 34.27 \mathrm{bc} & 18.34 \mathrm{~d} & 53.51 \mathrm{c} \\ 5 & \text { Fig } & 84.34 \mathrm{~b} & 48.59 \mathrm{bc} & 57.61 \mathrm{~d} \\ \text { S. Error } & & 3.57 & 3.87 & 2.09 \\ \text { LSD } & & 7.57 & 8.69 & 5.03\end{array}$

The guava was found most preferred host for $B$. zonata which contradicts with earlier scientists who had described the mango as the most suitable host for oviposition in both field as well as laboratory conditions (Sarwar et al., 2013; El-Gendy, 2017). The contradiction may be because we did not use mango as a host in current study due to offseason or unavailability. Adult emergence was found highest on guava as compared to citrus, banana and apple. Many other researchers had reported that adult emergence was recorded maximum in apple fruit (E1-Gendy, 2017) which is not in line with our study findings. The current study showed that maximum number of pupae was formed in guava host while minimum in apple fruit.

\section{Conclusions and Recommendations}

Host suitability is the most important for their survival of off-spring. The female fruit fly determines host/food distance using sensory organ with the help of sensory receptors. After the selection of host fly land and taste food as a sample that food is suitable or not for their progeny survival based on food nutrition and host defense toxicity. So, the study concluded that the guava was more preferable fruit for oviposition among the tested fruits.

\section{Acknowledgments}

Authors are highly thankful to MNS. University of Agriculture, Multan for facilitating during experiment.

\section{Novelty Statement}

Fruit fly, Bactrocera zonata (Saunders) is the most important fruits and vegetables pest and cosmopolitan in nature. So, host suitability is the most important for their survival of off-spring. This study will be helpful to scientists regarding oviposition preference of B. zonata.

\section{Author's Contribution}

Ghulam Murtaza: Wrote the manuscript and conducted the experiment.

Muhammad Ramzan: Helped in data analysing.

Assad Ullah and Abid Ali: Collected data.

Ayesha Zafar: Helped in references.

Rukhsar Beanish and Ghulam Mustafa: Wrote the manuscript.

Ahmad Ali and Mudassar Aslam: Reviewed the manuscript.

\section{Conflict of interest}

The authors have declared no conflict of interest.

\section{References}

Clarke, A.R., K.F. Armstrong, A.E. Carmichael, J.R. Milne, S. Raghu, G.K. Roderick and D.K. Yeates. 2005. Invasive phytophagous pests arising through a recent tropical evolutionary radiation: The Bactrocera dorsalis complex of fruit flies. Annu. Rev. Entomol., 50: 293-319. https://doi.org/10.1146/annurev. ento.50.071803.130428

De Meyer, M., M.P. Robertson, M.W. Mansell, S. Ekesi, K. Tsuruta, W. Mwaiko, J.F. Vayssieres and A.T. Peterson. 2010. Ecological niche and potential geographic distribution of the Invasive Fruit Fly Bactrocera invadens (Diptera, Tephritidae). B. Entomol. Res., 100: 35-48. https://doi.org/10.1017/S0007485309006713 
El-Akhdar, E.A.H. and Y.E. Afia. 2009. Functional ultrastructure of antennae, wings and their associated sensory receptors of peach fruit fly, Bactrocera zonata (Saunders) as influenced by the sterilizing dose of gamma irradiation. J. Rad. Res. Appl. Sci., 2: 797- 817.

El-Gendy, I.R., 2017. Host preference of the peach fruit fly, Bactrocera zonata (Saunders) (Diptera: Tephritidae), under laboratory conditions. J. Entomol., 14(4): 160-167. https://doi. org/10.3923/je.2017.160.167

Fontellas-Brandalha, T.M.L. and F.S. Zucoloto. 2004. Selection of oviposition sites by wild Anastrepha obliqua (Macquart) (Diptera: Tephritidae) based on the nutritional composition. Neotrop. Entomol., 33: 557562. https://doi.org/10.1590/S1519566X2004000500003

Jakson, C.G., R.I. Vargas and D.Y. Suda. 2003. Populations of Bactrocera cucurbitae (Diptera: Tephritidae) and its parasitoid, Psyttalia fletcheri (Hymenoptera: Braconidae) in Coccinia grandis (Cucurbitaceae) or ivy gourd on the island of Hawaii. Proc. Hawaiian Entomol. Soc., 36: 39-46.

Joachim-Bravo, I.S., O.A. Fernandes, S.A. DeBortoli and F.S. Zucoloto. 2001. Oviposition behavior of Ceratitis capitata Wiedemann (Diptera: Tephritidae): Association between oviposition preference and larval performance in individual females. Neotrop. Entomol., 30: 559-564. https://doi.org/10.1590/S1519566X2001000400008

Joomaye, A., N.S. Price, J.M. Stonehouse and I. Seewooruthun. 2000. Quarantine pest risk analysis of fruit flies in the Indian Ocean: the case of Bactrocera zonata. In: Price, N.S., Seewooruthun, I., editors. Proceedings of the Indian Ocean Commissio, Regional Fruit Fly Symposium, Flic en Flac 2000; $5^{\text {th }}-9^{\text {th }}$ June 2000; Reduit, Mauritius. Regional Fruit Fly Programme, Ministry of Agriculture, Food Technol. Nat. Reso., pp. 179-183.

Mahfuza, K., B.R. Tahira and J. Howlader. 2011. Comparative Host Susceptibility, Oviposition, and Colour Preference of Two Polyphagous Tephritids: Bactrocera cucurbitae (Coq.) and Bactrocera tau (Walker). Res. J. Agri. Biol. Sci., 7(3): 343- 349.

Ni, W.L., Z.H. Li, H.J. Chen, F.H. Wan, W.W. Qu, Z. Zhang and D.J. Critics. 2012. Including climate change in pest risk assessment: the peach fruit fly,Bactrocera zonata (Diptera:Tephritidae). Bull. Entomol. Res., 102(2): 17383. https://doi. org/10.1017/S0007485311000538

Rasool, B., M. Rafique, M. Asrar, R. Rasool, M. Adeel, A. Rasul and F. Jabeen. 2017. Host preference of Bactrocera flies species (Diptera: Tephritidae) and parasitism potential of Dirhinus giffardii and Pachycropoideus vindemmiae under laboratory conditionss. Pak. Entomol., 39(1): 17-21.

Rauf, I., N. Ahmad, S.M.S. Rashdi, M. Ismail and M.H. Khan. 2013. Laboratory studies on ovipositional preference of the peach fruit fly Bactrocera zonata (Saunders) (Diptera: Tephiritidae) for different host fruits. Afr. J. Agri. Res., 8(15): 1300-1303. https://doi. org/10.5897/AJAR2013.6744

Sarwar, M., M. Hamed, B. Rasool, M. Yousaf and M. Hussain. 2013. Host preference and performance of fruit flies Bactrocera zonata (Saunders) and Bactrocera cucurbitae (Coquillett) (Diptera: Tephritidae) for various fruits and vegetables. Int. J. Scient. Res. Environ. Sci., 1: 188-194. https://doi.org/10.12983/ ijsres-2013-p188-194

Uchoa, M.A. and J.N. Nicacio. 2010. New records of Neotropical fruit flies (Tephritidae), lance flies (Lonchaeidae) (Diptera: Tephritoidea), and their host plants in the South Pantanal and adjacent areas, Brazil. Ann. Entomol. Soc. Am., 103(5): 723-733. https://doi.org/10.1603/ AN09179

Vargas, R.I., J.C. Pinero and L. Leblanc. 2015. An overview of pest species of Bactrocera fruit flies (Diptera: Tephritidae) and the integration of biopesticides with other biological approaches for their management with a focus on the Pacific region. Insects, 6(2): 297-318. https:// doi.org/10.3390/insects6020297

Wisotsky, Z., A. Medina, E. Freeman and A. Dahanukar. 2011. Evolutionary differences in food preference rely on $\mathrm{Gr} 64 \mathrm{e}$, a receptor for glycerol. Nat. Neurosci., 14: 1534-1531. https:// doi.org/10.1038/nn.2944

Zubair, U., A. Shehzad, M.I. Mastoi and K. Mahmood. 2019. New record of fruit flies (Diptera: Tephritidae) from Poonch division of Azad Jammu and Kashmir. Pak. J. Agric. Res., 32(3): 466-473. https://doi.org/10.17582/ journal.pjar/2019/32.3.466.473 